\title{
Quantitative Approach in Enhancing Decision Making Through Big Data as An Advanced Technology
}

\author{
Hana Yousuf ${ }^{1, *}$, Asma Yousuf Zainal ${ }^{2}$ \\ ${ }^{1}$ Faculty of Engineering \& IT, The British University in Dubai, 345015, United Arab Emirates \\ ${ }^{2}$ Faculty of Business Management, The British University in Dubai, 345015, United Arab Emirates
}

\begin{tabular}{l} 
A R T I C L E I N F O \\
\hline Article history: \\
Received: 23 July, 2020 \\
Accepted: 23 August, 2020 \\
Online: 09 September, 2020
\end{tabular}

Keywords:

Big Data

Discussion Making

Quantitative Method

Percentage Analysis

Chi-Square

Correlation Analysis

Regression Analysis

\begin{abstract}
A B S T R A C T
The technology of Big Data got the capability to process large amounts of data, manage them effectively and make retrieval whenever it is required. Decision making in any organisation is a challenging task since decisions need to be made based on the accessibility of data and its status, this becomes more challenging especially in large organisations that generate massive amount of information and data every single day. Implementation of latest advanced technologies like Big Data is imperative for any organization to make decisions which reduces time and pave the fourth industrial revolution. Even though this is vital in today's business world, there are still few organizations that are hesitant to adopt it.

This paper illustrates the relation between Big Data and effective decision making by implementing a quantitative analysis through questionnaire. The conducted analysis is implemented using SPSS through correlational perspective, where percentage analysis, Chi-Square, correlation, and regression analyses are performed to obtain results.

It is clearly depicted that large organizations transition to adopt Big Data to aid their decision making, where medium and smaller organizations were slowly transitioning the adoption. In spite of this, most of employees, irrespective of the type of organization agree that Big Data is indeed a powerful advanced technology as they were satisfied by the organizational direction they have taken.
\end{abstract}

\section{Introduction}

\subsection{Background}

Digital technologies are transforming the way organizations function sparking the necessity for creative approaches and a wide range of highly functional presentations [1]. Facilities of storing have grown drastically in the past years along with data collection approaches where large amounts of data are also becoming readily accessible. In every moment, new set of data are being generated by various sources, these data need to be processed and evaluated in new forms to derive value. In addition, organizations should get as much value as possible from enormous sources $\&$ amounts of data stored [2]. Further technologies and devices are available now to corporations and people to generate and collect more data from various groups. These days, an individual entity can own multiple devices, where each device carries extremely large amount of vital information. These types of information are described as Big Data,

*Corresponding Author: Hana Yousuf, The British University in Dubai, Tel: +971501010008, Email: hana.yousuf@gmail.com.

www.astesj.com

https://dx.doi.org/10.25046/aj050515 or data with a volume, velocity, variety and depth that standard techniques make it difficult to handle [3].

Big Data can contain various combinations of data including texts with social emotions, news feeds, site logfiles for audio / video, as well as geographical and location data, Multimedia, xml data, etc [4]. Due to the size, wide range, dramatic changes, different types of storage and analytical techniques, such these information needs fresh type of Big Data analytics. The rising of these kinds of information need to utilize a Big Data and take advantage of its capability in the organizations who have already a clear, simple roadmap and guidelines for managing Big Data in their departments.

Organizations today are enabled to achieve their target and exceed it if they were able to adopt new technologies which consequently leads to generating profit from Big Data analysis. In other sectors, the capability to create transition would distinguish those who are going to lead and those who are going to left behind. Nevertheless, conducting data analysis only is not enough, it must 
be circulated effectively to the employees within the organization in attempt to influence decisions and therefore obtain specific role at the heart of decision-making processes instead of intuition [5]. In order to make smart choices, organizations should be sharing right information to the right individuals at the right time [6]. As such, Big Data attains great expectations, and the effect on enhancing the decision has been explored by various researchers, with McAfee \& Brynjolfsson as the strategic front-runners. However, since it is a relatively new area of concept and research, it is essential to have more empirical studies in specific sectors to the research of what impacts Big Data analytics will have on decision-making.

Organizations need contract terms and interpersonal governance, Big Data analytics competences, information sharing, coordination, process integration, flexible infrastructure, quality data sources and decision making qualities to effectively manage a large data chain and make quality decisions $[7,8]$. Contract compliance relates to the formalization of arrangements with Big Data vendors to increase the consistency of the results. Relational governance that involves collaboration and information sharing for data interpretation and processing maintains trust between organizational entities. To design a Big Data network and overcome the smaller data groups, various participants of the organisation who are part of the Big Data based decision-making environment require collaboration. It is also necessary to connect operations and procedures to cut the price of Big Data and its related analytics. Big Data networks and its operations must be part of the organizational routine, since this will enhance information speed. The flexibility of the network often allows data collection and retrieval. Information accuracy, with respect to the data provider's interest, is also necessary to avoid making mistake decisions that may prove to be quite expensive. In fact, decisionmakers will have the capacity to analyse the findings of Big Data analyses and consider their consequences in order to strengthen evidence-driven decision-making capabilities and increase consistency [7].

\subsection{Problem Statement}

Existing literature on the use of Big Data for decision making system focuses primarily on the issues and advantages of business intelligence and Big Data[8], whereas the practical effects of Big Data analysis to improve business intelligence are still relatively under-researched[9][10][11]. Some research is usually focused on methods, technical issues and their possible solutions in using Big Data analytics for business intelligence, but there is a shortage of literature on the practical implications of using Big Data analytics in general for decision making.

\subsection{Research Questions}

This research aims to understand employee's perception of Big Data among in enhancing decision making systems. Therefore, the research questions are:

- How relevant is Big Data for decision making in an organization?

- What percentage of the organizations are currently using Big Data?

- Do the employees feel that Big Data is relevant in the current scenarios?

\subsection{Literature Review}

Big Data is increasingly transforming the way businesses make choices, because new decision-making skills are required in the Big Data era in order to make better judgments [7]. In the available research the dynamic capabilities are often used to address the strengths of Big Data analytics [12].

This research explores the antecedents of large data decision taking capability. Even though its potential effect has been described with respect to the dynamic capabilities $[13,14]$, many elements of the organizations that affect the Big Data sustaining value of a firm remain unexplored.

The capacity of Big Data has defined by [7] as the capacity of a business to start making high-quality Big Data based decisions by handling a Big Data network effectively. [15] have also presented crucial and in-depth insights into diverse Big Data functionalities; however, the study is much more applicable to Big Data value creation. Conversely, the factors that affect the quality of Big Data decision making has discussed by [7]. Effective management of a Big Data networks requires organizations to build up their capacity and capabilities for Big Data management and analytics. The related literature also demonstrates the ability of a organization to interpret data can affect its efficiency and that the ability of the Big Data processing and analytics organizations to make strategic decision is likely to impact.

Leadership plays a vital role in the development and reconfiguration of dynamic capabilities as an effective way of providing direction to organizational members [6]. The leadership contingency principle often implies members will produce the required results by choosing their leadership style appropriately [16]. The existing literature also recognizes the effect of leadership style on various organizational and the behavioural outcomes for example, a leadership focus on knowledge management influences it positively within an organization [17], [18]. Leaders can also influence the information analysis trend by adopting appropriate leadership behaviours [19].

Leadership is an essential impactor of Big Data development, which is generally done through procedure, social and systemic interactions and complementarities [20]. It is further agreed by [21] that leadership is essential to a firm's development of using technology. Specifically, it is correlated with leadership propensity to adapt, understanding of incentives to improve current practices and services in a constructive way, and desire and capacity to incorporate these improvements. Managerial leadership cognition is critical to the improvement of Diagnostic Control Systems (DCS) that are used to manage the environment change [22].

In a wide spectrum of firms, talent management, which is emerging as a key organizational challenge, is considered very important [23]. Researchers have concluded that, despite the limited consequences of current talent management for implementing Big Data, its role in various situations and environments needs to be analysed [24]. Considering the essential function of the talent harnessing, indicated that the application of Big Data may be improved by effective talent management. As information is now more cost effective for organizations, the data analysis components have become more valuable, which means it is easier to hire data scientists. 
The growing worth of Big Data specialists makes retaining them valuable to the organizations. While the expertise of statistics is essential, the use of Big Data demands more than conventional statistical abilities. Big Data management requires specific techniques and abilities that might not be easily available at certain locations [25], but are commonly held by the current generation of informatics scientists. Big Data use also requires skills involved in data cleaning and visualization, which suggests that organizations need to nurture key talents The acknowledgment by [26] that HR experts and expertise play in a Big Data setting, who are able to speak the market language and therefore make it easy for leaders to devise strategies to tackle Big Data.

According to the existing literature, efficient talent management practices improve organizational decision-making capabilities [27]. The resource-based perspective suggests organizations should use their strategic resources to achieve sustained competitive advantages [28]. The knowledge-based view argues that knowledge which is connected to its staff is the most essential strategic asset of a firm [18]. Using employee knowledge and skills to reap the maximum benefit., for instance, as long as success is concerned, organizations will incorporate acceptable talent acquisition practices, as indicated in the literature on the usage of Big Data [15].

The decision-making on data analytics requires quality decision-makers and Big Data analysts experts, asserted done by [7] . In addition to performing data analysis, the latter will also deal with contract terms and interpersonal leadership to improve information cooperation and information sharing across organization boundaries, which can affect the quality of Big Data decision. A lack of dedicated talent has been perceived as the major barrier to capturing value from Big Data [25]. Even though there are currently lots of professionals working with Big Data, there is a great amount of talent shortage for the next three to five years [28].

Many developing countries are in the race to utilize AI capabilities linked to Big Data; therefore, effective talent management is essential for businesses to reap the benefits of Big Data and digital technology[29]. As data gets cheaper, the domain's scientists become much more valuable, that further rises the need for integrated talent management procedures to hire, retain and recruit employees required at all levels to fulfil the standards of data analytics aimed at quality decision making. As such, effective talent management plays a significant role in building capacity for organizations [30]-[31].

\section{Methodology}

\subsection{Research Design}

Quantitative methodology is used in this work to gather data and conduct the necessary analysis. It is a type of research method that performs mathematical, computational, and statistical approaches using quantifiable data. To carry out the study, the data must be gathered entirely first. Until obtaining the results, the appropriate sample population must be defined depending upon the necessity. Here the target group is the employees of corporate organizations, about the use of Big Data for decision making. The research design will be as correlational research, where percentage analysis, Chi-Square analysis, correlation analysis and regression analysis will be applied.

It is necessary to identify the respondent population to compile the data and to build the questionnaire. Since the work deals with usage of Big Data in different organisations, employees of these organisations must be considered as community sample. Other related technologies like working of Big Data and its advantages which are related to the principles of Big Data and decision making have been extensively discussed in the literature review section.

The data are gathered in the form of questionnaires from specified respondents. The questions are posed to the respondents in the questionnaire, esponses are compiled. The questionnaire are posted directly in the form of (google forms) and sent via email. The answers must be translated into the graphical format for quantitative methods, so that they are appropriate for study. Any variables are established during the study for grouping the questions and answers into categories. There are numerous factors that rely heavily on this to be considered. In this work, it is identified whether the organisations are willing to use Big Data for decision making, and whether they have trust in them. The employees of certain organisations are taken into account for collecting the data for this study.

\subsection{Scaling}

Scaling is done to simplify data analysis and enable the researchers to better understand the data. Likert scaling is used in this work. Likert scale suggests that an ability / magnitude of attitude is linear, i.e. on a scale from strongly agreeing to disagreeing, and appears to conclude that attitudes will be calculated. There are various types of Likert scale depending on the number of opinions that are captured for each question [32]. A 4-point Likert scale is used in this research which contains 4 options, which are: Strongly Agree, Agree, Disagree and Strongly Disagree.

\subsection{Questionnaire Development}

The survey questions are deemed more accurate for gathering answers, they are used to gather answers in this research. The biggest drawback in utilizing questionnaires is that the queries tend to be determined at the outset and the subsequent questions cannot be changed on the basis of the first query. In this work, though, only a few questions will be asked, questionnaires are enough. A questionnaire that contains various questions related to the use of bigdata for decision making, and its effectiveness in enhancing the decision-making process is used. The questionnaire consists of a total of ten questions and it is attached in the appendix. Questions 2 and 3 can be considered as independent responses, while the other questions are dependent on these two questions.

\subsection{Sampling Technique}

When survey is conducted, there are different ways the population sample must be identified. This is because, it won't be feasible to conduct analysis with the entire population. In this case, we must conduct the study on the employees working small, medium and large organizations, where there would be millions of employees around the world. Hence, certain mixture of small- and large-scale organizations are identified randomly. The research paper will adopt Random Sampling technique. 


\subsection{Field Work}

The respondents are randomly chosen and the questionnaires built using Google forms. The employees working in the same research field of different organisations are identified and the form sent to them by emails. Even though the forms are shared with many employees, only some of them had responded, out of which we round the number of respondents to 50 response. The answers are collected in a single dataset, and then SPSS tools used to perform different statistical approaches for quantitative research.

\section{Data Analysis}

\subsection{Methodology}

The responses are obtained from the respondents and then analysed through SPSS tool. The methodology used here are the percentage analysis, Chi-square test, correlation analysis, and regression analysis. The collected data analysed in form of statistical analysis as part of quantitative methodology.

Percentage analysis is among the simple mathematical methods that is commonly utilized in primary data processing and understanding. This deals with the number of respondents to a specific query is the proportion arrived from the overall chosen population for the analysis. A Chi-square test is a mathematical hypothesis check that is true while the Chi-square function is applied under the null hypothesis, called the Chi-square test of Pearson and its variants. Correlation coefficient is a statistical calculation of any form of correlation which implies a statistical association between two variables. The variables may be two columns of a specified series of results, also referred to as a survey, or major aspects of a random multivariate vector with a defined distribution. Regression analysis is an effective mathematical tool that analyses the association between two or more relevant variables. While there are several forms of regression analysis, they all analyse at the heart the effect of one or more independent variables on a dependent variable

\section{Result}

\subsection{Percentage Analysis}

Out of the four techniques, percentage analysis first analysed as given below. Out of the 50 respondents, 25 respondents, which considered as $50 \%$ of the respondents worked in a medium scale organization that had between 100 and 500 as shown in Table 1. The rest of the respondents were range between small and large organizations where $24 \%$ employed in small organizations less than 100 employees, and 26\% employed in organizations more than 500 employees.

Table 1: Employees contribution based on the organization size

\begin{tabular}{|l|l|l|}
\hline Organization Size & Frequency & Percent \\
\hline $1-100$ employees & 12 & 24.0 \\
\hline $100-500$ employees & 25 & 50.0 \\
\hline More than 500 employees & 13 & 26.0 \\
\hline Total & 50 & 100 \\
\hline
\end{tabular}

The number of respondents whose organization work with Big Data is shown in table 2. Most of the respondents are using Big
Data in their organisation systems which is around $72 \%$ in, whereas $20 \%$ of the respondents' organizations did not use Big Data and $8 \%$ said that their organization is studying the implementation of Big Data in near future as shown in Table 2.

Table 2: Organization working with Big Data

\begin{tabular}{|l|l|l|}
\hline Response & \multicolumn{1}{|c|}{ Frequency } & Percentage \\
\hline Yes & 36 & 72.0 \\
\hline No & 10 & 20.0 \\
\hline In future & 4 & 8.0 \\
\hline Total & 50 & 100.0 \\
\hline
\end{tabular}

Out of the smaller organizations below 100 employees, around $67 \%$ of them are using Big Data in decision making, while $25 \%$ of them are not using it and $8 \%$ will implement it soon. Among the medium scale organization with employees between 100 and $500,60 \%$ of them are using Big Data in making decision, while $28 \%$ of them are not using it and $12 \%$ will implement it soon. Among the large organizations with more than 500 employees, all of them use Big Data for decision making systems. The result is shown in Table 3

Table 3: employees' implantation and preference in using Big Data

\begin{tabular}{|c|c|l|c|c|}
\hline $\begin{array}{c}\text { Employee } \\
\text { Size }\end{array}$ & Frequency & Implementation & $\begin{array}{c}\text { Working } \\
\text { with Big } \\
\text { Data }\end{array}$ & Percentage \\
\hline \multirow{2}{*}{$\begin{array}{c}1-100 \\
\text { Employees }\end{array}$} & \multirow{2}{*}{12} & $\begin{array}{l}\text { Not } \\
\text { implemented }\end{array}$ & 3 & $25.00 \%$ \\
\cline { 3 - 5 } & & $\begin{array}{l}\text { Soon will be } \\
\text { implemented }\end{array}$ & 1 & $8.33 \%$ \\
\hline \multirow{2}{*}{$\begin{array}{c}100-500 \\
\text { employees }\end{array}$} & \multirow{2}{*}{25} & $\begin{array}{l}\text { Implemented } \\
\text { implemented }\end{array}$ & 15 & $60 \%$ \\
\hline & & $\begin{array}{l}\text { Soon will be } \\
\text { implemented }\end{array}$ & 3 & $12 \%$ \\
\hline \multirow{2}{*}{$\begin{array}{l}\text { Imployees } \\
\text { Employ }\end{array}$} & \multirow{2}{*}{13} & $\begin{array}{l}\text { Implemented } \\
\text { implemented }\end{array}$ & 13 & $100 \%$ \\
\hline & $\begin{array}{l}\text { Soon will be } \\
\text { implemented }\end{array}$ & 0 & $0 \%$ \\
\hline
\end{tabular}

The importance of the Big Data as recorded from the employee working in different organization size is shown in Table 4. $68 \%$ of the respondents said that it is very necessary for making decisions in the organization, while $24 \%$ slightly agreed and thought it is might be necessary to be implemented in some 
departments and only $8 \%$ of the respondents felt that it is not necessary at all.

Table 4: Importance of Big Data in decision making

\begin{tabular}{|l|l|l|}
\hline Response & Frequency & \multicolumn{1}{c|}{ Percentage } \\
\hline Not Necessary & 4 & 8.0 \\
\hline Slightly necessary & 12 & 24.0 \\
\hline Very necessary & 34 & 68.0 \\
\hline Total & 50 & 100.0 \\
\hline
\end{tabular}

The availability of some form of strategy for Big Data is shown in Table 5. While $32 \%$ of the respondents confirmed that there is some form of strategy being used by the company for decision making analysis, $34 \%$ of them said that there is no strategy for this, while another $34 \%$ of them were not sure of this.

Table 1: Availability of Big Data strategies

\begin{tabular}{|l|r|r|}
\hline Response & Frequency & \multicolumn{1}{|c|}{ Percentage } \\
\hline $\begin{array}{l}\text { There is a strategy for } \\
\text { Big Data }\end{array}$ & 16 & 32.0 \\
\hline $\begin{array}{l}\text { There isn't a strategy } \\
\text { for Big Data }\end{array}$ & 17 & 34.0 \\
\hline $\begin{array}{l}\text { Not sure of the } \\
\text { availability of a } \\
\text { strategy for Big Data }\end{array}$ & 17 & 34.0 \\
\hline Total & 50 & 100.0 \\
\hline
\end{tabular}

\subsection{Chi-Square Test}

Chi-square test is used which checks the null hypothesis between different questions. Since the second question influences the other questions, its relationship and hypothesis with other questions are tabulated in tables 6 to 8 . The Chi-square value for having a strategy for Big Data, and those working with Big Data is shown in table 6. There are 16 respondents that use Big Data in the organization besides a strategy for usage and implementation, which accounts to $32 \%$ of the overall respondents. $20 \%$ of the respondents neither use Big Data nor have any strategy for Big Data in the organization. Around 26\% of the respondents use Big Data but are not sure whether the organization have any kind of strategy adopts the Big Data implementation or not. A Chi-square of 31.2 is obtained for the relation, and p-value is 0 , which shows that this is significant.

Table 2: Association between organisation work with Big Data and organization has any strategy for Big Data

\begin{tabular}{|c|c|c|c|c|}
\hline \multirow{2}{*}{$\begin{array}{c}\text { Organization } \\
\text { work with Big } \\
\text { Data }\end{array}$} & \multicolumn{2}{|c|}{$\begin{array}{c}\text { Organization have any strategy } \\
\text { for Big Data }\end{array}$} & \multirow{3}{*}{ Total } & \multirow{2}{*}{$P$-value } \\
\cline { 2 - 3 } & Yes & No & Not sure & \\
\cline { 2 - 3 } & \multicolumn{3}{|c|}{ n(\%) } & \\
\hline
\end{tabular}

\begin{tabular}{|c|c|c|c|c|c|}
\hline Yes & $16(100.0)$ & $\begin{array}{l}7 \\
(41.2)\end{array}$ & $13(76.5)$ & $\begin{array}{l}36 \\
(72.0) \\
\end{array}$ & \multirow{4}{*}{$0.000 * *$} \\
\hline No & $\begin{array}{l}0 \\
(0.0)\end{array}$ & $10(58.8)$ & $\begin{array}{l}0 \\
(0.0)\end{array}$ & $\begin{array}{l}10 \\
(20.0)\end{array}$ & \\
\hline In future & $\begin{array}{l}0 \\
(0.0) \\
\end{array}$ & $\begin{array}{l}0 \\
(0.0)\end{array}$ & \begin{tabular}{|l}
4 \\
$(23.5)$ \\
\end{tabular} & $\begin{array}{l}4 \\
(8.0) \\
\end{array}$ & \\
\hline Total & $16(100.0)$ & $17(100.0)$ & $17(100.0)$ & $\begin{array}{l}50 \\
(100.0)\end{array}$ & \\
\hline
\end{tabular}

Chi-Square: $31.209, * * \mathrm{P}<0.001$

Similar analysis is done for those working with Big Data and for those organisations that have qualified experts in Big Data. Most of the experts, $72 \%$ agree that they have a qualified expert, since their organization works with Big Data. $20 \%$ of the respondents do not work with Big Data and claim that they do not have any qualified Big Data experts. It has a very high Chi-square value of 50 , and $p$-value of 0 , showing that the result is significant as shown in table 7 .

Table 7: Association between organization work with Big Data and organization with qualified Big Data experts

\begin{tabular}{|c|c|c|c|c|c|c|}
\hline $\begin{array}{l}\text { Importance } \\
\text { of using Big }\end{array}$ & Organiza & $\begin{array}{r}\text { ion with qt } \\
\text { exper }\end{array}$ & $\begin{array}{l}\text { alified B } \\
s\end{array}$ & ig Data & \multirow{3}{*}{ Total } & \multirow{3}{*}{$\begin{array}{c}P \\
\text { value }\end{array}$} \\
\hline $\begin{array}{l}\text { Data for } \\
\text { decision }\end{array}$ & $\begin{array}{l}\text { Strongly } \\
\text { Disagree }\end{array}$ & Disagree & Agree & $\begin{array}{c}\text { Strongly } \\
\text { agree } \\
\end{array}$ & & \\
\hline making & \multicolumn{2}{|c|}{$\mathrm{n}(\%)$} & \multicolumn{2}{|c|}{ n(\%) } & & \\
\hline Not Necessary & $\begin{array}{r}4 \\
(100.0) \\
\end{array}$ & $\begin{array}{r}0 \\
(0.0) \\
\end{array}$ & $\begin{array}{r}0 \\
(0.0) \\
\end{array}$ & $\begin{array}{r}0 \\
(0.0) \\
\end{array}$ & $\begin{array}{r}4 \\
(8.0) \\
\end{array}$ & \\
\hline $\begin{array}{l}\text { Slightly } \\
\text { necessary }\end{array}$ & $\begin{array}{r}0 \\
(0.0) \\
\end{array}$ & $\begin{array}{r}0 \\
(0.0) \\
\end{array}$ & $\begin{array}{r}3 \\
(20.0) \\
\end{array}$ & $9(31.0)$ & $\begin{array}{r}12 \\
(24.0) \\
\end{array}$ & $0.00 *$ \\
\hline $\begin{array}{l}\text { Very } \\
\text { necessary }\end{array}$ & $\begin{array}{r}0 \\
(0.0) \\
\end{array}$ & $\begin{array}{r}2 \\
(100.0) \\
\end{array}$ & $\begin{array}{r}12 \\
(80.0) \\
\end{array}$ & $\begin{array}{r}20 \\
(69.0) \\
\end{array}$ & $\begin{array}{r}34 \\
(68.0) \\
\end{array}$ & $*$ \\
\hline Total & $\begin{array}{r}4 \\
(100.0)\end{array}$ & $\begin{array}{r}2 \\
(100.0) \\
\end{array}$ & $\begin{array}{r}15 \\
(100.0) \\
\end{array}$ & $\begin{array}{r}29 \\
(100.0) \\
\end{array}$ & $\begin{array}{r}50 \\
(100.0)\end{array}$ & \\
\hline
\end{tabular}

Chi-Square: $50.000, * * \mathrm{P}<0.001$

Similar Chi-square analysis is done for the opinion of importance of working with Big Data and whether the organization has qualified experts. $64 \%$ of the respondents feel that using Big Data is necessary and have qualified experts. Out of this $40 \%$ strongly agree, and $24 \%$ generally agree. Among those who feel Big Data is necessary, only $4 \%$ think that they do not have a qualified expert. With correlation too, a high Chisquare value of 51.48 is obtained along with significant results as shown in Table 8.

\subsection{Correlation Analysis}

Correlation analysis is performed to identify the correlation between two questions. The correlation coefficient implies the statistical association between two variables. Here, the variables are the two columns of the results. The correlation between the questions 2, 6, 7 and 10 are given in table 14. The questions 6,7, and 10 depend on question 2, they have high amount of correlation 
with one another. All the coefficients have a value about 0.6 , with some even exceeding 0.87 as shown in Table 9.

Table 3: Association between qualified experts and importance of working with Big Data

\begin{tabular}{|c|c|c|c|c|c|c|}
\hline \multirow{3}{*}{$\begin{array}{l}\text { Importance of } \\
\text { using Big Data } \\
\text { for decision } \\
\text { making }\end{array}$} & \multicolumn{4}{|c|}{$\begin{array}{c}\text { Organization with qualified Big Data } \\
\text { experts }\end{array}$} & \multirow{3}{*}{ Total } & \multirow{3}{*}{$\begin{array}{c}P \\
\text { value }\end{array}$} \\
\hline & $\begin{array}{l}\text { Strongly } \\
\text { Disagree }\end{array}$ & Disagree & Agree & $\begin{array}{c}\text { Strongly } \\
\text { agree }\end{array}$ & & \\
\hline & \multicolumn{2}{|c|}{ n(\%) } & \multicolumn{2}{|c|}{ n(\%) } & & \\
\hline Not Necessary & $\begin{array}{r}4 \\
(100.0) \\
\end{array}$ & $\begin{array}{r}0 \\
(0.0) \\
\end{array}$ & $\begin{array}{r}0 \\
(0.0) \\
\end{array}$ & $\begin{array}{r}0 \\
(0.0) \\
\end{array}$ & $\begin{array}{r}4 \\
(8.0)\end{array}$ & \\
\hline $\begin{array}{l}\text { Slightly } \\
\text { necessary }\end{array}$ & $\begin{array}{r}0 \\
(0.0) \\
\end{array}$ & $\begin{array}{r}0 \\
(0.0) \\
\end{array}$ & $\begin{array}{r}3 \\
(20.0) \\
\end{array}$ & $\begin{array}{r}9 \\
(31.0) \\
\end{array}$ & $\begin{array}{r}12 \\
(24.0) \\
\end{array}$ & 0.00 \\
\hline Very necessary & $\begin{array}{r}0 \\
(0.0) \\
\end{array}$ & $\begin{array}{r}2 \\
(100.0)\end{array}$ & $\begin{array}{r}12 \\
(80.0) \\
\end{array}$ & $\begin{array}{r}20 \\
(69.0) \\
\end{array}$ & $\begin{array}{r}34 \\
(68.0) \\
\end{array}$ & $* *$ \\
\hline Total & $\begin{array}{r}4 \\
(100.0)\end{array}$ & $\begin{array}{r}2 \\
(100.0)\end{array}$ & $\begin{array}{r}15 \\
(100.0)\end{array}$ & $\begin{array}{r}29 \\
(100.0)\end{array}$ & $\begin{array}{r}50 \\
(100.0)\end{array}$ & \\
\hline
\end{tabular}

Chi-Square: $51.481, * * \mathrm{P}<0.001$

Table 9: Correlations analysis organization with Big Data

\begin{tabular}{|c|c|c|c|c|}
\hline Questions & $\begin{array}{c}\text { Organization } \\
\text { working with } \\
\text { Big Data }\end{array}$ & $\begin{array}{c}\text { Organization } \\
\text { with } \\
\text { qualified Big } \\
\text { Data experts }\end{array}$ & $\begin{array}{c}\text { Satisfied } \\
\text { with the } \\
\text { organization } \\
\text { in the } \\
\text { integration } \\
\text { of Big Data } \\
\text { tools in the }\end{array}$ & $\begin{array}{l}\text { Organization } \\
\text { uses other } \\
\text { tools in } \\
\text { besides Big } \\
\text { Data for } \\
\text { decision } \\
\text { making. }\end{array}$ \\
\hline $\begin{array}{c}\text { Organization } \\
\text { work with } \\
\text { Big Data }\end{array}$ & 1 & & & \\
\hline $\begin{array}{l}\text { Organization } \\
\text { contains } \\
\text { qualified Big } \\
\text { Data experts. }\end{array}$ & $.874^{* *}$ & 1 & & \\
\hline $\begin{array}{c}\text { Satisfied } \\
\text { with the } \\
\text { organization } \\
\text { in the } \\
\text { integration of } \\
\text { Big Data } \\
\text { tools in the }\end{array}$ & $.659^{* *}$ & $.661^{* *}$ & 1 & \\
\hline $\begin{array}{l}\text { Organization } \\
\text { uses other } \\
\text { tools in } \\
\text { besides Big } \\
\text { Data for } \\
\text { decision } \\
\text { making }\end{array}$ & $.659^{* *}$ & $.661^{* *}$ & $.870^{* *}$ & 1 \\
\hline
\end{tabular}

The correlation between the questions 3, 5, 8 and 9 are given in table 10. The questions 5,8 , and 9 depend on question 2, they have high amount of correlation with one another. While compared to the previous table, the correlation coefficient is slightly lesser. All the coefficients have a value about 0.35 , with some even exceeding 0.5 as shown.

\subsection{Regression Analysis}

Regression analysis analyses the association between two or more relevant variables. Here, the correlation between the dependent and the independent variables are assigned. The www.astesj.com regression between the 3impact of decision making and the importance of Big Data for decision making is shown in table 11. The Beta represents the slope of the line which shows that the line is very much dependent on the former variable. The standard error is low at 0.185 . Hence, the points are not very much spread out from the main line. From the test value of 3.993 , the probability variable is calculated, which comes at 0 , showing that result is significant.

Table 4: Correlations analysis

\begin{tabular}{|c|c|c|c|c|}
\hline Question & $\begin{array}{c}\text { Important } \\
\text { of Big } \\
\text { Data in } \\
\text { decision } \\
\text { making }\end{array}$ & $\begin{array}{c}\text { Organizations } \\
\text { impact of the } \\
\text { decision it } \\
\text { makes. }\end{array}$ & $\begin{array}{c}\text { Reduces } \\
\text { uncertainty } \\
\text { in making } \\
\text { decisions }\end{array}$ & $\begin{array}{c}\text { Improve } \\
\text { decision } \\
\text { making } \\
\text { process in an } \\
\text { organization }\end{array}$ \\
\hline $\begin{array}{c}\text { Important of } \\
\text { Big Data in } \\
\text { decision } \\
\text { making }\end{array}$ & 1 & 1 & & \\
\hline $\begin{array}{c}\text { Organizations } \\
\text { impact of the } \\
\text { decision it } \\
\text { makes. }\end{array}$ & $.499^{* *}$ & $.389^{* *}$ & 1 & \\
\hline $\begin{array}{c}\text { Reduces } \\
\text { uncertainty in } \\
\text { making } \\
\text { decisions }\end{array}$ & $.518^{* *}$ & & & \\
\hline $\begin{array}{c}\text { Improve } \\
\text { decision } \\
\text { making } \\
\text { process in an } \\
\text { organization }\end{array}$ & $.518^{* *}$ & $.389^{* *}$ & $.560^{* *}$ & \\
\hline
\end{tabular}

$* * \mathrm{p}<0.001$

H11: There is a significant impact of the importance of Big Data in decision making on the organisations impact for decision making, which is the dependent variable. Hence, there is no null hypothesis here, and there is an alternate hypothesis. The probabilistic values must be less than 0.001 , hence ours shows significant results.

Table 5: Association between important Big Data for decision making and organizations' impact for decision making

\begin{tabular}{|c|c|c|c|c|c|}
\hline & \multicolumn{2}{|c|}{$\begin{array}{c}\text { Unstandardized } \\
\text { Coefficients } \\
\end{array}$} & \multirow[t]{2}{*}{ R-Square } & \multirow[t]{2}{*}{ t value } & \multirow[t]{2}{*}{$P$ value } \\
\hline & Beta & SE & & & \\
\hline (Constant) & 1.116 & 0.496 & & 2.251 & 0.029 \\
\hline $\begin{array}{l}\text { Importance of } \\
\text { Big Data for } \\
\text { decision making }\end{array}$ & 0.740 & 0.185 & 0.249 & 3.993 & $0.000 * *$ \\
\hline
\end{tabular}

Dependent Variable: Organizations' impact for decision making, ${ }^{*} *_{\mathrm{p}}<0.001$ SE: Standard Error

The regression for the association between the organisations working with Big Data and the availability of strategies of Big Data for decision making is shown in table 12. The Beta represents the slope of the line at 0.391 which shows that the line is very much dependent on the former variable. The standard error is low at 0.179 . Hence, the points are not very much spread out from the main line. From the test value of 2.1888 , the probability 
variable is calculated, which comes at 0 , showing that result is significant.

H11: There is a significant impact of the organisations working with bigdata on the strategies used for Big Data in the organization, which is the dependent variable. Hence, there is no null hypothesis here, and there is an alternate hypothesis. The probabilistic values must be less than 0.001 , hence ours shows significant results.

Table 6: Association between Organization work with Big Data and Strategies for Big Data for analytics

\begin{tabular}{|l|r|r|r|r|r|}
\hline & \multicolumn{2}{|c|}{$\begin{array}{c}\text { Unstandardized } \\
\text { Coefficients }\end{array}$} & \multirow{2}{*}{ R-Square } & t value & \multirow{2}{*}{$\boldsymbol{P}$ value } \\
\cline { 2 - 3 } & Beta & \multicolumn{1}{|c|}{ SE } & & & \\
\hline (Constant) & 1.488 & 0.268 & & 5.556 & 0.000 \\
\hline $\begin{array}{l}\text { Organization work } \\
\text { with Big Data }\end{array}$ & 0.391 & 0.179 & 0.191 & 2.188 & $0.000^{* *}$ \\
\hline
\end{tabular}

Dependent Variable: Strategies for Big Data for analytics, $* * p<0.001$ SE: Standard Error

The regression for the association between the organisations working with Big Data and the satisfaction of using Big Data is shown in table 13. The Beta represents the slope of the line at 1.193. The standard error is low at 0.179 . Hence, the points are not very much spread out from the main line. From the test value of 6.071 , the probability variable is calculated, which comes at 0 , showing that result is significant.

H11: There is a significant impact of the organisations working with bigdata on the satisfaction of using Big Data in the organization, which is the dependent variable. Hence, there is no null hypothesis here, and there is an alternate hypothesis. The probabilistic values must be less than 0.001 , hence ours shows significant results.

Table 7: Association between Organization work with Big Data and Satisfaction

\begin{tabular}{|l|r|r|r|r|r|}
\hline & \multicolumn{2}{|c|}{$\begin{array}{c}\text { Unstandardized } \\
\text { Coefficients }\end{array}$} & \multirow{2}{*}{ R-Square } & t value & P value \\
\cline { 2 - 3 } & Beta & SE & & & \\
\hline (Constant) & 4.582 & 0.294 & & 15.585 & 0.000 \\
\hline $\begin{array}{l}\text { Organization work } \\
\text { with Big Data }\end{array}$ & 1.193 & 0.196 & \multirow{2}{*}{0.434} & & \\
\hline
\end{tabular}

Dependent Variable: Satisfaction, $* * \mathrm{p}<0.001$

SE: Standard Error

\section{Conclusions and Recommendations}

From the above analysis, it is depicted that most of the large organizations have already transitioned to using Big Data for decision making in their companies, where medium scale and smaller scale organizations are slowly transitioning. In spite of that, most employees regardless of the type of their organizations agree that Big Data technology is useful, and they are also satisfied by the organization on the direction they have taken. This work has presented a quantitative methodology for understanding the perception of Big Data used in their company. Initially, a brief introduction on decision making and Big Data systems were studied, followed by relevant literature were illustrated in the literature review section. A questionnaire was initiated to perform interview on the public to understand their perception Big Data. Data is collected in through online forms and then analysed through SPSS. The results illustrate that Big Data is very much relevant in the current scenario in corporate organizations. Most of the organizations seem to have already implemented Big Data for decision making purposes and others are rapidly following their footsteps. The same perception was accepted by employees too, where they showcased that using Big Data is indeed useful and most of the employees are satisfied with the way their company is using Big Data.

\section{Limitation and Caveats}

The Big Data technology can be used to improve effectiveness of decision-making systems. This work used SPSS as a tool to perform percentage analysis, Chi-square, correlation analysis, and regression analysis. The main limitations that hinders the adoption of Big Data is its awareness and knowledge. Many managers are still struggling with older technologies and are not ready to adopt them soon due to fear of change and its related challenges. Upgrading and seeking expert advice can be a good approach to convince them to adopt Big Data. In the future, the same analysis can be performed with more in-depth questions based on different organizational sectors. This work has only used quantitative methodology. In the future, both quantitative and qualitative methodology can be implemented to explore further. There are no caveats to consider in this work.

\section{Acknowledgment}

This work is a part of a project undertaken at the British University in Dubai.

\section{References}

[1] S. Brunswicker, E. Bertino, S. Matei, "Big Data for Open Digital Innovation - A Research Roadmap,” Big Data Research, 2(2), 53-58, 2015, doi:10.1016/j.bdr.2015.01.008.

[2] M.C.M. Oo, T. Thein, An efficient predictive analytics system for high dimensional big data, Journal of King Saud University - Computer and Information Sciences, 2019, doi:10.1016/j.jksuci.2019.09.001.

[3] S. Fan, R.Y.K. Lau, J.L. Zhao, Demystifying Big Data Analytics for Business Intelligence Through the Lens of Marketing Mix, Big Data Research, 2(1), 28-32, 2015, doi:10.1016/j.bdr.2015.02.006.

[4] P. Törnberg, A. Törnberg, "The limits of computation: A philosophical critique of contemporary Big Data research,” Big Data and Society, 5(2), 2018, doi: $10.1177 / 2053951718811843$

[5] M. Muniswamaiah, T. Agerwala, C. Tappert, "Big Data in Cloud Computing Review and Opportunities," International Journal of Computer Science and Information Technology, 11(4), 43-57, 2019 , doi:10.5121/ijcsit.2019.11404.

[6] P.J.H. Schoemaker, S. Heaton, D. Teece, "Innovation, Dynamic Capabilities, and Leadership," California Management Review, 61(1), 1542, 2018, doi:10.1177/0008125618790246.

[7] M. Janssen, H. van der Voort, A. Wahyudi, "Factors influencing big data decision-making quality," Journal of Business Research, 70, 338-345, 2017, doi:10.1016/j.jbusres.2016.08.007.

[8] A.Y. Zainal, H. Yousuf, S.A. Salloum, "Dimensions of Agility Capabilities Organizational Competitiveness in Sustaining," in Joint European-US 
Workshop on Applications of Invariance in Computer Vision, Springer: 762-772, 2020.

[9] H. Yousuf, M. Lahzi, S.A. Salloum, K. Shaalan, Systematic Review on Fully Homomorphic Encryption Scheme and Its Application, Springer: 537-551, 2021, doi:10.1007/978-3-030-47411-9 29.

[10] S.A. Salloum, M. Al-Emran, K. Shaalan, "Mining Social Media Text: Extracting Knowledge from Facebook," International Journal of Computing and Digital Systems, 6(2), 2210-142, 2017, doi:10.12785/ijcds/060203.

[11] S.A. Salloum, M. Al-Emran, K. Shaalan, A. Tarhini, "Factors affecting the E-learning acceptance: A case study from UAE," Education and Information Technologies, 24(1), 509-530, 2019, doi:10.1007/s10639018-9786-3.

[12] S.F. Wamba, A. Gunasekaran, S. Akter, S.J. fan Ren, R. Dubey, S.J. Childe, "Big data analytics and firm performance: Effects of dynamic capabilities," Journal of Business Research, 70, 356-365, 2017, doi:10.1016/j.jbusres.2016.08.009.

[13] S. Erevelles, N. Fukawa, L. Swayne, "Big Data consumer analytics and the transformation of marketing," Journal of Business Research, 69(2), 897904, 2016, doi:10.1016/j.jbusres.2015.07.001.

[14] R. Dubey, A. Gunasekaran, S.J. Childe, Z. Luo, S.F. Wamba, D. Roubaud, C. Foropon, "Examining the role of big data and predictive analytics on collaborative performance in context to sustainable consumption and production behaviour," Journal of Cleaner Production, 196, 1508-1521, 2018, doi:10.1016/j.jclepro.2018.06.097.

[15] J. Zeng, K.W. Glaister, "Value creation from big data: Looking inside the black box," Strategic Organization, 16(2), 105-140, 2018, doi:10.1177/1476127017697510.

[16] Organisational Behaviour - Stephen Robbins, Timothy A. Judge, Bruce Millett, Maree Boyle - Google Books.

[17] M.J. Donate, J.D. Sánchez de Pablo, "The role of knowledge-oriented leadership in knowledge management practices and innovation," Journal of Business Research, 68(2), 360-370, 2015, doi:10.1016/j.jbusres.2014.06.022.

[18] S. Shamim, S. Cang, H. Yu, "Impact of knowledge oriented leadership on knowledge management behaviour through employee work attitudes," International Journal of Human Resource Management, 30(16), 2387-2417, 2019, doi:10.1080/09585192.2017.1323772.

[19] S. Shamim, S. Gang, H. Yu, "Influencers of information system usage among employees for knowledge creation. A future research agenda," in SKIMA 2016 - 2016 10th International Conference on Software, Knowledge, Information Management and Applications, Institute of Electrical and Electronics Engineers Inc.: 134-141, 2017, doi:10.1109/SKIMA.2016.7916210.

[20] T. Felin, N.J. Foss, K.H. Heimeriks, T.L. Madsen, "Microfoundations of Routines and Capabilities: Individuals, Processes, and Structure," Journal of Management Studies, 49(8), 1351-1374, 2012, doi:10.1111/j.14676486.2012.01052.x.

[21] O. Koryak, K.F. Mole, A. Lockett, J.C. Hayton, D. Ucbasaran, G.P. Hodgkinson, "Entrepreneurial leadership, capabilities and firm growth," International Small Business Journal: Researching Entrepreneurship, 33(1), 89-105, 2015, doi:10.1177/0266242614558315.

[22] M. Waleed Fakhr, M. Lahzi Gaid, G. Ibrahim Selim, Secure Translation Using Fully Homomorphic Encryption and Sequence-to-Sequence Neural Networks, 2018.

[23] D.G. Collings, K. Mellahi, W.F. Cascio, "Global Talent Management and Performance in Multinational Enterprises: A Multilevel Perspective," Journal of Management, 45(2), 540-566, 2019, doi: $10.1177 / 0149206318757018$.

[24] T.N. Krishnan, H. Scullion, "Talent management and dynamic view of talent in small and medium enterprises," Human Resource Management Review, 27(3), 431-441, 2017, doi:10.1016/j.hrmr.2016.10.003.

[25] P. Tambe, "Big data investment, skills, and firm value," Management Science, 60(6), 1452-1469, 2014, doi:10.1287/mnsc.2014.1899.

[26] D. Angrave, A. Charlwood, I. Kirkpatrick, M. Lawrence, M. Stuart, "HR and analytics: why HR is set to fail the big data challenge," Human Resource Management Journal, 26(1), 1-11, 2016, doi:10.1111/17488583.12090 .

[27] L.J. Gutierrez-Gutierrez, V. Barrales-Molina, H. Kaynak, "The role of human resource-related quality management practices in new product development: A dynamic capability perspective," International Journal of Operations and Production Management, 38(1), 43-66, 2018, doi:10.1108/IJOPM-07-2016-0387.

[28] J.B. Barney, D.J. Ketchen, M. Wright, "The Future of Resource-Based Theory," Journal of Management, 37(5), 1299-1315, 2011, doi:10.1177/0149206310391805.

[29] H. Yousuf, A.Y. Zainal, M. Alshurideh, S.A. Salloum, Artificial Intelligence Models in Power System Analysis, Springer: 231-242.

[30] W.F. Joyce, J.W. Slocum, “Top management talent, strategic capabilities, and firm performance," Organizational Dynamics, 41(3), 183-193, 2012, doi:10.1016/j.orgdyn.2012.03.001.

[31] A. Almansoori, M. AlShamsi, S.A. Salloum, K. Shaalan, Critical Review of Knowledge Management in Healthcare, Springer: 99-119, 2021, doi:10.1007/978-3-030-47411-9 6 .

[32] D. Kriksciuniene, V. Sakalauskas, R. Lewandowski, "Evaluating the Interdependent Effect for Likert Scale Items," in Lecture Notes in Business Information Processing, Springer: 26-38, 2019, doi:10.1007/978-3-03036691-9_3. 